\title{
ARTICLE
}

\section{Cannabidiol does not display drug abuse potential in mice behavior}

\author{
Adrián Viudez-Martínez ${ }^{1}$, María S. García-Gutiérrez ${ }^{1,2}$, Juan Medrano-Relinque ${ }^{1}$, Carmen M. Navarrón ${ }^{1}$, Francisco Navarrete ${ }^{1,2}$ and \\ Jorge Manzanares ${ }^{1,2}$
}

\begin{abstract}
Recent evidence suggests that cannabidiol (CBD) may be useful for the treatment of different neuropsychiatric disorders. However, some controversy regarding its profile as a drug of abuse hampers the further development of basic and clinical studies. In this study, the behavioral profile of CBD as a potential drug of abuse was evaluated in C57BL/6J mice. Reinforcing properties of CBD (15, 30 , and $60 \mathrm{mg} / \mathrm{kg}$; i.p.) were assessed using the conditioned place preference (CPP) paradigm. Spontaneous withdrawal symptoms and motor activity in the open field were examined $12 \mathrm{~h}$ after the last CBD administration (30 mg/kg/12 h, i.p., 6 days). CBD plasma concentrations were measured at 2, 4, 8, 12, and $24 \mathrm{~h}$ after the administration of CBD (30 mg/kg, i.p.). Furthermore, an oral CBD selfadministration paradigm ( $50 \mathrm{mg} / \mathrm{kg}$; CBD water-soluble $1.2 \mathrm{mg} / \mathrm{mL}$ ) was performed to evaluate whether this drug produced any effects on motivation compared with a non-reinforcing substance (water). We found that CBD failed to induce CPP, withdrawal symptoms, or altered motor behavior $12 \mathrm{~h}$ after its administration. At that time, only traces of CBD were detected, ensuring that the lack of alterations in somatic signs and locomotor activity was not due to residual drug in plasma. Interestingly, mice displayed similar motivation and consumption of CBD and water. Taken together, these results show that CBD lacks activity as a drug of abuse and should stimulate the development of the basic and clinical studies needed to elucidate its potential therapeutic use for the treatment of neuropsychiatric and drug use disorders.
\end{abstract}

Keywords: cannabidiol; cannabinoid receptor; drug abuse; conditioned place preference; oral CBD self-administration; withdrawal syndrome

Acta Pharmacologica Sinica (2019) 40:358-364; https://doi.org/10.1038/s41401-018-0032-8

\section{INTRODUCTION}

The plant Cannabis sativa contains more than 400 natural compounds, 120 of which are phytocannabinoids [1-3]. The main psychotropic constituent is delta-9-tetrahydrocannabinol $\left(\Delta^{9}\right.$ THC), isolated for the first time by Gaoni and Mechoulam [4]. $\Delta^{9}$ THC mediates the rewarding properties of cannabis through binding to specific G-protein-coupled receptors, mainly the cannabinoid type 1 receptor $\left(\mathrm{CB}_{1} \mathrm{R}\right)$ [5]. In contrast, the structure of cannabidiol (CBD), the second major ingredient of cannabis, was characterized by Mechoulam et al. [6]. This compound appears to lack activity as a drug of abuse [6] due to its low affinity on $\mathrm{CB}_{1}$ Rs (100-fold lower affinity than THC) [7].

In the last two decades, a variety of research groups have examined the effects of CBD in basic and clinical studies. The results obtained suggest that $C B D$ has beneficial effects highly relevant for the management of neurological disorders such as epilepsy [8-10], multiple sclerosis [11, 12], Parkinson's disease $[13,14]$, and Alzheimer's disease [15, 16]. Moreover, there is a large body of evidence revealing that CBD improves cognition [17] and neurogenesis [18, 19] with anxiolytic [20-23], antidepressant [24-26], and antipsychotic-like effects [27-32], supporting its potential usefulness for the treatment of neuropsychiatric and drug-use disorders.
The mechanisms underlying these effects are still not well understood [33] but seem to include more than 65 key targets $[34,35]$. To date, the orphan G-protein-coupled receptor GPR55, the intracellular vanilloid, the nuclear peroxisome proliferatoractivated receptor- $\gamma$, and the serotonin $5-\mathrm{HT}_{1 \mathrm{~A}}$ receptor appear to be crucial for the effects of CBD [9, 20,35-37]. In addition, CBD is a putative inhibitor of anandamide reuptake and hydrolysis, and the adenosine transporter, indirectly increasing the levels of this endocannabinoid and adenosine, respectively [37-39]. Although $\mathrm{CBD}$ appears to indirectly activate $\mathrm{CB}_{1} \mathrm{R}$ by increasing anandamide levels, several studies have also identified $C B D$ as a negative allosteric modulator of $C B_{1} R$ [40]. Furthermore, there is evidence suggesting that $\mathrm{CBD}$ seems to act as an inverse agonist or antagonist of the cannabinoid type 2 receptor $\left(\mathrm{CB}_{2} \mathrm{R}\right)[1,41,42]$.

Despite the number of findings suggesting the potential therapeutic use of $C B D$, there is some controversy regarding its profile as a drug of abuse. CBD is currently classified as a Schedule 1 drug according to the United Nations Single Convention on Narcotic Drugs of 1961 and the Comprehensive Drug Abuse Prevention and Control Act of the United States [43]. A Schedule 1 controlled substance is defined by the Controlled Substance Act (CSA) as a substance presenting "no currently accepted medical use, a lack of accepted safety for the use under medical

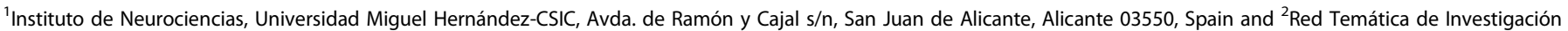
Cooperativa en Salud (RETICS), Red de Trastornos Adictivos, Instituto de Salud Carlos III, MICINN and FEDER, Madrid, Spain

Correspondence: Jorge Manzanares (jmanzanares@goumh.umh.es)

Received: 18 December 2017 Accepted: 20 April 2018

Published online: 18 July 2018 
supervision, and a high potential for abuse". Furthermore, CBD is classified as a Schedule 2 drug according to the Controlled Drugs and Substances Act in Canada also inferring "a high potential for abuse which may lead to severe psychological or physical dependence" [44]. This fact significantly hampers the further development of basic and clinical studies, even though there is no scientific/experimental evidence supporting these considerations [40]. To date, no previous studies have been specifically designed to evaluate the potential properties of CBD as a drug of abuse, but several studies have suggested that CBD lacks potential as a drug of abuse. This assumption is based on the lack of an autonomic response (euphoria or intoxication) in patients treated with CBD [45-47] and the failure of CBD to induce conditioned place preference (CPP) in two animal studies [48, 49]. However, no further behavioral assays commonly used for the evaluation of drug addiction have been performed.

To shed light on the potential properties of $C B D$, this study evaluated the behavioral profile of $C B D$ as a potential drug of abuse by using widely accepted behavioral tests for the evaluation of different aspects of drug addiction: attentional bias, motivation to consume, and withdrawal syndrome. Dose-response effects of CBD were tested in the CPP test, symptoms of potential spontaneous withdrawal syndrome (motor activity and withdrawal signs after the cessation of CBD administration) were evaluated, and oral CBD self-administration was tested in C57BL/6J mice.

\section{MATERIALS AND METHODS}

Animals

Male C57BL/6J mice from Harlan (Barcelona, Spain) weighing $20-25 \mathrm{~g}$ were housed in groups of six per cage $(40 \times 25 \times 22 \mathrm{~cm})$ under controlled conditions (temperature, $21 \pm 2{ }^{\circ} \mathrm{C}$; relative humidity, $60 \pm 10 \% ; 12 \mathrm{~h}$ light/dark cycle, lights on from 08:00 to 20:00). Behavioral analyses were initiated 1 week after acclimatization to the animal room and were performed by placement of the home cage in the operant-task room during the development of conditioning experiments. All studies were conducted in compliance with the Spanish Royal Decree 1201/ 2005, the Spanish Law 32/2007, and the European Union Directive of 22 September, 2010 (2010/63/UE), regulating the care of experimental animals.

\section{Drugs}

For CPP and the evaluation of CBD withdrawal syndrome, CBD was obtained from STI Pharmaceuticals (Essex, UK), dissolved in ethanol:cremophor:saline (1:1:18), and injected intraperitoneally (i.p.) at the appropriated doses (CPP: 15, 30, and $60 \mathrm{mg} / \mathrm{kg}$; CBD withdrawal syndrome: $30 \mathrm{mg} / \mathrm{kg} / 12 \mathrm{~h}, 6$ days).

For the oral CBD self-administration procedure, water-soluble CBD (purified CBD organic plant extract, $99.9 \%$ purity (highperformance liquid chromatography (HPLC)), total THC content (\%) $<0.01 \%$; CBD Pur US, Hilton Head Island, SC, USA) was purchased. This formulation is a water-soluble powder with certain excipients that increase the oral bioavailability of CBD. The water-soluble CBD contains $99.9 \%$ pure CBD, arabic gum, maltodextrin, and polyphosphates, and is a nano-sized formulation to avoid the stickinessrelated problems of CBD. CBD was immediately dissolved in distilled water $\left(37^{\circ} \mathrm{C}\right)$ before its use, following the instructions of the manufacturer, at the desired concentration $(50 \mathrm{mg} / \mathrm{kg} ; \mathrm{CBD}$ water-soluble solution $(1.2 \mathrm{mg} / \mathrm{mL}))$. This concentration was calculated considering the average number of active lever presses (50), the volume released in each lever's activation $(25 \mu \mathrm{L})$, and the weight of the mice to provide a final dose of $50 \mathrm{mg} / \mathrm{kg}$.

Dose-response effects of CBD on CPP

CPP was performed following a protocol previously described [50]. The CPP apparatus consisted of two compartments $(30 \times 20 \times$ $20 \mathrm{~cm}$ ), one black with a smooth plastic floor and the other one white with a stainless-steel grid floor, separated by a sliding door. The CPP procedure consisted of three phases as follows:

(A) Pre-conditioning (Pre-C) phase: on day 1, mice were placed between the two compartments and allowed free access to the entire apparatus for a period of $20 \mathrm{~min}$. Mice that spent more than $75 \%$ of time in any of the two compartments were discarded from the experiment.

(B) Conditioning phase: on days $2-11$, the animals were randomized and assigned to the vehicle (VEH) or CBD groups (15, $30,60 \mathrm{mg} / \mathrm{kg}$; i.p.) ( $n=8 /$ group). CBD groups were counterbalanced for chamber type (context $A / B$ ) associated with VEH and CBD. Animals remained in the conditioned compartment for $15 \mathrm{~min}$.

(C) Test day: on day 12, the door was opened and mice were placed in the center to allow free exploration of the two compartments. The time that mice spent in each compartment was recorded during the $15 \mathrm{~min}$ session using the SMART (Spontaneous Motor Activity Recording and Tracking) software system (Panlab, Barcelona, Spain).

\section{Determination of plasma CBD concentrations}

Before the evaluation of the CBD withdrawal syndrome, plasma concentrations of $C B D$ were measured to confirm that there was no significant amount of $C B D$ remaining in the blood that could disturb the interpretation of the results.

Briefly, after a single administration of CBD (30 mg/kg; i.p.), trunk blood was collected from mice at different time points $(2,4$, $8,12$, and $24 \mathrm{~h})$. The extraction and analysis of plasma was performed using a method previously described with some modifications [51]. Aliquots of $0.1 \mathrm{~mL}$ of plasma were transferred to $12 \mathrm{~mL}$ glass tubes and spiked with CBD-d3 (Sigma-Aldrich, Madrid, Spain). After dilution with $0.1 \mathrm{M}$ ammonium acetate buffer ( $\mathrm{pH} 4.0)$, samples were extracted with tert-butyl methyl ether. The dry organic extracts were reconstituted in $75 \mu \mathrm{L}$ of a mixture of water:acetonitrile $(10: 90, \mathrm{v} / \mathrm{v})$ with $0.1 \%$ formic acid $(\mathrm{v} / \mathrm{v})$. Detection of $\mathrm{CBD}$ in plasma was performed using an Agilent 1200 series HPLC system (Agilent Technologies, CA, USA) coupled to a 6410 Triple Quadrupole LC-MS (Agilent Technologies) mass spectrometer with an electrospray interface. Chromatographic separation was achieved on a C18-CSH column $(3.1 \times 100 \mathrm{~mm}$, $1.8 \mu \mathrm{m}$ particle size) (Waters Corp., Milford, MA, USA) at $40^{\circ} \mathrm{C}$. The electrospray ion source was set on the positive ionization mode. The mass spectrometry detection was done by single-reaction monitoring. Quantification was calculated with the slope (s), intercept, and correlation coefficient $(r)$ by weighting the $(1 / x)$ least-squares linear regression of the peak area ratio (analyte/IS) vs. the concentration of the standard. The detection limit and quantification limit of the analytical procedure were 0.15 and 0.45 $\mathrm{ng} / \mathrm{mL}$, respectively.

\section{CBD withdrawal syndrome}

The analysis of the CBD withdrawal syndrome was carried out according to a protocol previously described by our group for cannabinoid spontaneous withdrawal $[52,53]$. Briefly, CBD (30 mg/ kg; i.p.) or VEH were administered twice a day for 6 days $(n=$ 8/group). On day $7,12 \mathrm{~h}$ after the last administration of CBD or the corresponding $\mathrm{VEH}$, motor activity and behavioral withdrawal signs (rearing, grooming, and rubbing) were evaluated during a 15 min period (see schematic representation, Fig. 3a).

Motor activity was recorded using SMART software and withdrawal signs were recorded using video cameras, and further analyzed by a blind observer.

Oral CBD self-administration paradigm

Oral CBD self-administration paradigm was based on a method previously described by our group with some modifications [54]. Oral CBD self-administration tests were carried out in 12 modular operant chambers (Panlab, Harvard Apparatus) equipped with a chamber light, two levers, one receptacle to receive a drop of liquid 


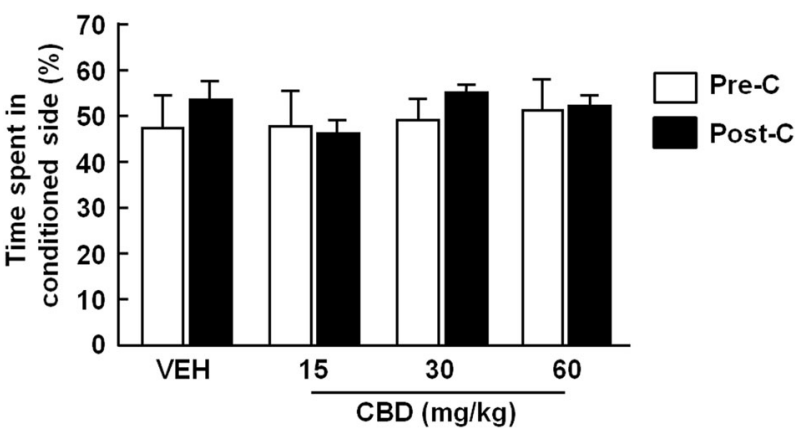

Fig. 1 Evaluation of conditioned place preference for cannabidiol (CBD) in C57BL/6J mice. Columns represent the percentage of total time spent in the drug-paired side for the different doses of CBD (15, 30 , and $60 \mathrm{mg} / \mathrm{kg}$, i.p.) or vehicle (VEH) groups during the preconditioning (Pre-C) and post-conditioning (Post-C) tests

solution, one syringe pump, one stimulus light, and one buzzer. Packwin software (Panlab) controlled the stimulus and fluid delivery, and recorded the operant responses. Pressing one lever did not produce any action (inactive lever), whereas pressing the other lever delivered $25 \mu \mathrm{L}$ of fluid combined with the delivery of a $0.5 \mathrm{~s}$ light stimulus and a $0.5 \mathrm{~s}, 2850 \mathrm{~Hz}, 85 \mathrm{~dB}$ buzzer (active lever), followed by a $6 \mathrm{~s}$ timeout period. The experiment was divided into three phases as follows (see schematic representation, Fig. 4):

(A) Training phase: mice were given $1 \mathrm{~h}$ daily saccharin $(0.2 \%)$ self-administration sessions during days 1-10. During the first 5 days of the training phase, food was provided $1 \mathrm{~h}$ before the beginning of each session to increase the motivation for the active lever (postprandial). The following 5 days of the training phase and during the rest of the experiment, food access was provided after the end of each daily session (preprandial).

(B) Saccharin substitution phase: during this phase, the saccharin concentration was reduced and the CBD concentration was increased. Mice were given $1 \mathrm{~h}$ daily saccharin $0.15 \%+50 \mathrm{mg} / \mathrm{kg}$ CBD (CBD water-solution $1.2 \mathrm{mg} / \mathrm{mL}$ ) or VEH (days $11-13$ ), saccharin $0.1 \%+50 \mathrm{mg} / \mathrm{kg}$ CBD (CBD water-solution $1.2 \mathrm{mg} / \mathrm{mL}$ ) or VEH (days 14-16), and saccharin $0.05 \%+50 \mathrm{mg} / \mathrm{kg}$ (CBD water-solution 1.2 $\mathrm{mg} / \mathrm{mL}$ ) or VEH (days 17-19) sessions. Mice that maintained a stable response with $<30 \%$ deviation from the mean of the last three consecutive sessions and gave at least $75 \%$ of their responses on the active lever were selected for the following phase.

(C) $\mathrm{CBD}(50 \mathrm{mg} / \mathrm{kg}, 1.2 \mathrm{mg} / \mathrm{mL})$ consumption phase: for days 20-25, saccharin was removed from the solution and mice were given $50 \mathrm{mg} / \mathrm{kg}$ CBD (CBD water-solution $1.2 \mathrm{mg} / \mathrm{mL}$ ) or VEH for $1 \mathrm{~h}$ a day under a fixed ratio 1 (FR1) reinforcement schedule.

All solutions used in this paradigm were prepared daily, immediately before the beginning of the experimental procedure.

Statistical analysis

Statistical analyses were performed using one-way analysis of variance (ANOVA) with repeated measures (RM) followed by the Student-Newman-Keul test to compare CBD plasma concentrations at different time points. The CPP and oral CBD selfadministration paradigms data were analyzed using two-way ANOVA with RM followed by the Student-Newman-Keul test. Motor activity and somatic withdrawal signs (rearing, grooming, and rubbing) were analyzed using Student's $t$-test. Statistical analyses were performed with SigmaStat (Systat Software Inc., Chicago, IL, USA) software. Differences were considered significant if the probability of error was less than 0.05 .

\section{RESULTS}

Conditioned place preference

Statistical analysis revealed that CBD did not induce CPP at any of the doses evaluated $(15,30$, and $60 \mathrm{mg} / \mathrm{kg}$, i.p.). No differences

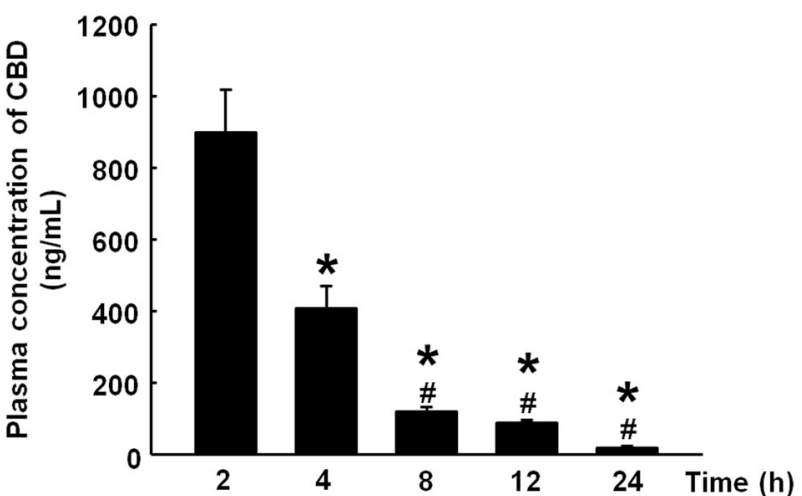

Fig. 2 Plasma concentration after a single administration of $C B D$ (30 mg/kg; i.p.). The columns represent the means \pm SEM. ${ }^{*} P<0.05$ vs. CBD plasma concentration at $2 \mathrm{~h}$. ${ }^{\#} P<0.05$ vs. CBD plasma concentration at $4 \mathrm{~h}$

were observed between the time spent in the drug-paired compartment during Pre- $C$ and post-conditioning at any of the CBD doses tested (Fig. 1) (two-way RM ANOVA followed by Student-Newman-Keuls test; treatment: $F(3,20)=0.305, \quad P=$ 0.821; time: $F(1,20)=1.104, P=0.306$; treatment $\times$ time: $F(3,20)=$ $0.535, P=0.663$ ). No differences between the groups were observed with respect to Pre-C scores.

\section{CBD plasma concentrations}

$\mathrm{CBD}$ plasma concentrations were significantly reduced after its administration ( $30 \mathrm{mg} / \mathrm{kg}$; i.p.). Indeed, after $8 \mathrm{~h}, \mathrm{CBD}$ plasma concentrations were reduced by $90 \%$ (Fig. 2) (one-way ANOVA followed by Student-Newman-Keuls test; $F(5,47)=38.532, P<$ $0.001)$.

CBD withdrawal syndrome

The cessation of CBD administration did not induce any alteration in motor activity or somatic signs. No significant differences in the distance travelled were observed between the CBD- and VEHtreated groups (Fig. 3b) (Student's $t$-test: $t=1.648,14 \mathrm{df}, P=$ 0.122). Furthermore, there were no differences in number of rearings (Student's $t$-test: $t=1.129,14 \mathrm{df}, P=0.278$, Fig. $3 \mathrm{c}$ ), groomings (Student's $t$-test: $t=-1.026,14 \mathrm{df}, P=0.322$, Fig. $3 \mathrm{~d}$ ), or rubbings (Student's $t$-test: $t=-1.163,14 \mathrm{df}, P=0.268$, Fig. 3e) between the CBD- and VEH-treated group.

\section{Oral CBD self-administration}

During the training phase, there were no differences in the number of effective responses (two-way RM ANOVA followed by Student-Newman-Keuls test, treatment, $F(1,239)=1.602$, $P=0.219$; day, $F(9,239)=37.847, \quad P<0.001$; treatment $x$ day, $\mathrm{F}(9,239)=0.547, P=0.839$, Fig. $4 \mathrm{~b})$ nor in the volume of fluid intake between both groups (two-way RM ANOVA, treatment, $F(1,239)=1.561, \quad P=0.225 ; \quad$ day, $F(9,239)=38.000, \quad P<0.001$; treatment $\times$ day, $F(9,239)=0.568, P=0.822$, Fig. 4e). Likewise, no differences were found between VEH- and CBD-treated mice during the substitution phase in the number of effective responses (two-way RM ANOVA followed by Student-NewmanKeuls test, treatment, $\mathrm{F}(1,215)=0.272, P=0.607$; day, $\mathrm{F}(8,215)=$ $12.155, \quad P<0.001$; treatment $\times$ day, $F(8,215)=1.293, \quad P=0.25$, Fig. 4c) nor in the volume of fluid intake (two-way RM ANOVA followed by Student-Newman-Keuls test, treatment, $F(1,215)=$ $1.82, P=0.191$; day, $\mathrm{F}(8,215)=10.204, P<0.001$; treatment $x$ day, $F(8,215)=1.035, P=0.412$, Fig. 4f).

During FR1 stage, no differences were found in the number of effective responses (two-way RM ANOVA followed by Student-Newman-Keuls test, treatment, $F(1,143)=0.176$, $P=0.679 ; \quad$ day, $\quad F(5,143)=2.394, \quad P<0.679 ; \quad$ treatment $x$ day, 
a
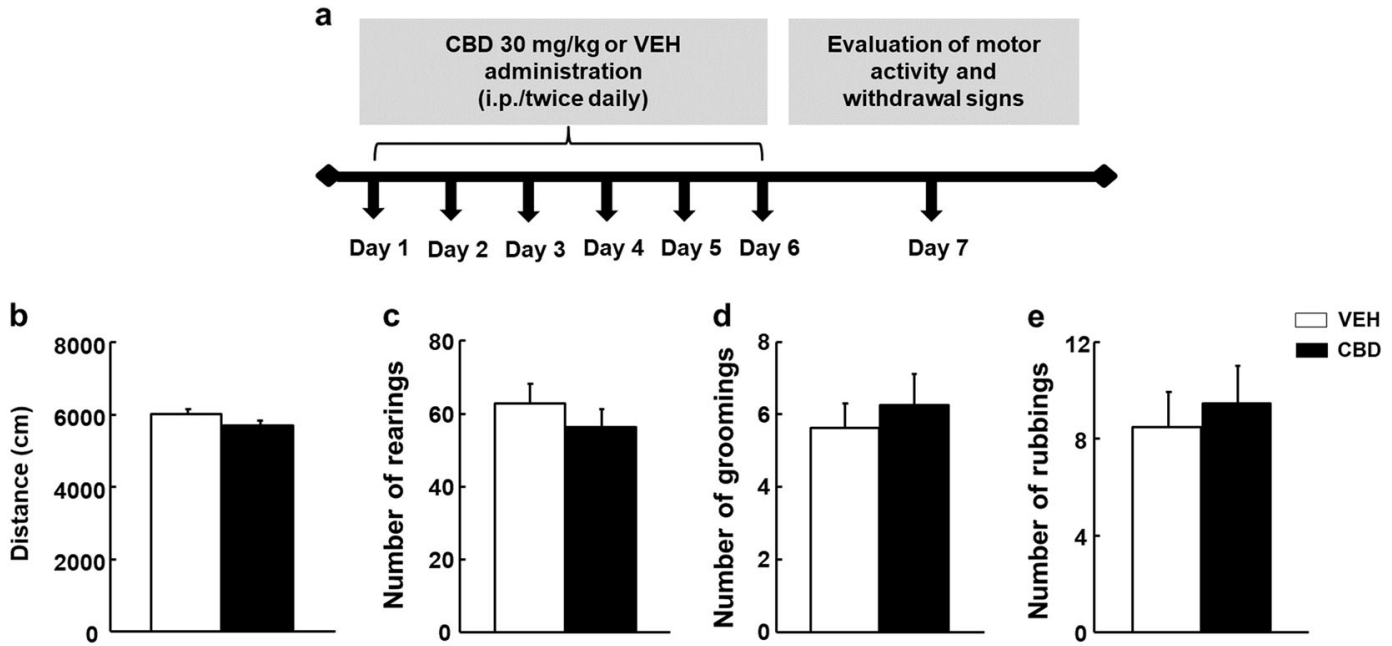

Fig. 3 Evaluation of potential CBD withdrawal signs. a Schematic diagram of the protocol used to evaluate CBD withdrawal signs in C57BL/6J mice. b Motor activity and quantification of $\mathbf{c}$ rearing, $\mathbf{d}$ grooming, and e rubbing in CBD-treated and vehicle (VEH)-treated mice. Data are means \pm SEM

$F(5,143)=0.352, P=0.880$, Fig. $4 d)$ nor in the volume of fluid intake between groups (two-way RM ANOVA followed by Student-Newman-Keuls test, treatment, $F(1,143)=0.134$, $P=0.718$; day, $\quad F(5,143)=5.033, \quad P<0.001$; treatment $\times$ day, $\mathrm{F}(5,143)=0.264, P=0.932$, Fig. $4 \mathrm{~g})$.

\section{DISCUSSION}

The present study demonstrates that CBD does not seem to present a pharmacological profile as a drug of abuse. This assumption is supported by the following observations: (1) the administration of CBD at different doses $(15,30,60 \mathrm{mg} / \mathrm{kg})$ did not induce any evidence of CPP; (2) cessation of CBD administration failed to induce a withdrawal syndrome, as neither locomotor activity alterations nor somatic withdrawal signs were detected $12 \mathrm{~h}$ after the last administration of CBD administration $(30 \mathrm{mg} / \mathrm{kg}$, twice daily, 6 days); and (3) CBD failed to induce oral selfadministration, as CBD did not increase the number of active lever presses nor the consumption during the FR1 schedule compared with water.

During the last two decades, CBD has been increasingly noted as a potential candidate for the treatment of different psychiatric and neurological disorders [9, 13, 15, 20, 24, 28]. Moreover, CBD has also shown potential utility for the treatment of drug-use disorders. For example, animal studies revealed that CBD reduced the reward-facilitating effect and withdrawal signs associated with morphine [55,56], heroin craving and relapse [57], and cocaine intake in rats [58]. In addition, our group demonstrated that the administration of CBD reduced ethanol consumption, motivation to drink, and relapse [59].

In humans, preliminary clinical studies have indicated that CBD induces a rapid decrease in cannabis withdrawal symptoms [60] and improves patient retention in withdrawal treatment [61]. Conversely, a different study showed that CBD failed to modify the subjective, reinforcing, or cardiovascular effects induced by smoked cannabis [62]. This disagreement may be due to the short period of CBD treatment, the experimental design (authors did not evaluate the long-term effect in abstinent patients to measure the relapse rate), and/or the oral administration of CBD, which provides a low bioavailability. Nevertheless, the available preclinical and clinical data suggest a high therapeutic potential of CBD for the management of drug-use disorders.

However, in some countries, CBD is still classified as a substance with abuse potential $[43,44]$, which hampers the development of further basic and clinical studies, and creates a misconception that does not match any scientific evidence/criteria [40]. In fact, available evidence suggests that CBD is not a drug of abuse in animals $[48,49]$ or humans [44-46]. Our study further supported this consideration by demonstrating that CBD did not exert drugabuse potential in any of the behavioral tests evaluated.

CPP, a well-established test used to determine whether a substance induces reinforcing properties [50, 63-65], was not produced by CBD at any of the doses tested $(15,30$, or $60 \mathrm{mg} / \mathrm{kg}$, i. p.). These results complement previous data reported by Vann et al. [49] demonstrating that CBD (1 and $10 \mathrm{mg} / \mathrm{kg}$ ) did not induce CPP in mice. Similarly, another study showed that CBD $(5 \mathrm{mg} / \mathrm{kg})$ did not induce CPP in rats [48]. Moreover, the present study also provides further information, as higher unexplored doses of CBD (30 and $60 \mathrm{mg} / \mathrm{kg}$, i.p.), commonly employed in other studies, were evaluated here. Taken together, these results strongly suggest that CBD does not induce CPP at low or high doses, indicating that $C B D$ does not induce reinforcing properties.

To evaluate whether CBD may induce a potential withdrawal syndrome, we examined locomotor activity and somatic signs after the cessation of repeated exposure to CBD, a common test used to assess withdrawal symptoms after the interruption of the administration of a drug with abuse potential $[52,66]$. Neither alterations in locomotor activity nor somatic signs (rearing, grooming, and rubbing) were observed $12 \mathrm{~h}$ after CBD cessation. The absence of CBD plasma concentrations $12 \mathrm{~h}$ after i.p. CBD administration confirmed that the lack of alterations in somatic signs and locomotor activity was not due to residual drug in the body.

Furthermore, this study also demonstrated that CBD failed to induce oral self-administration. The number of effective responses in FR1 phases revealed that the motivation to acquire CBD did not differ from a non-reinforcing substance (water). Notably, no differences were observed between the intake of CBD and water. Therefore, it seems plausible to discard a potential aversive effect induced by the taste of CBD that may mask the interpretation of the results. Indeed, the results provided are also in agreement with previous studies that demonstrated that the administration of $C B D$ in an intracranial self-stimulation paradigm also reduced brain reward function, suggesting that $C B D$ is unlikely to present abuse potential [55].

\section{CONCLUSIONS}

In summary, the present study provides further information suggesting that $C B D$ may not present reinforcing properties since 
a

\begin{tabular}{|c|c|c|c|c|}
\hline Training & \multicolumn{3}{|c|}{ Substitution (saccharin $\rightarrow$ CBD water-solution) } & \multirow[t]{2}{*}{ FR1 } \\
\hline Postprandial & \multicolumn{3}{|c|}{ Preprandial } & \\
\hline $0.2 \%$ saccharin & $\begin{array}{c}0.15 \% \text { saccharin } \\
+ \\
\stackrel{+}{\text { CBD } 50 \mathrm{mg} / \mathrm{kg}}\end{array}$ & $\begin{array}{c}0.1 \% \text { saccharin } \\
+ \\
\text { CBD } 50 \mathrm{mg} / \mathrm{kg}\end{array}$ & $\begin{array}{c}0.05 \% \text { saccharin } \\
+ \\
\text { CBD } 50 \mathrm{mg} / \mathrm{kg}\end{array}$ & $\begin{array}{c}0 \% \text { saccharin } \\
+ \\
\text { CBD } 50 \mathrm{mg} / \mathrm{kg}\end{array}$ \\
\hline
\end{tabular}

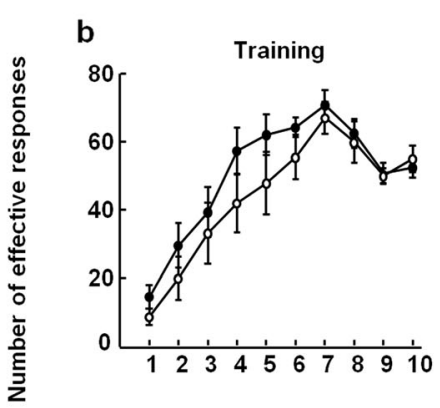

C

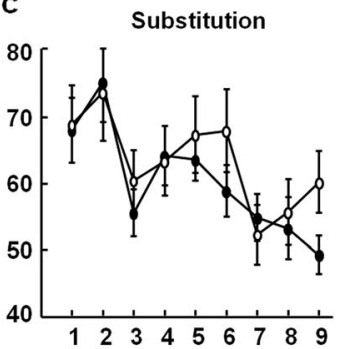

d FR1

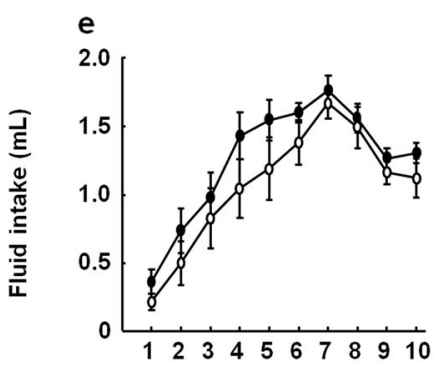

f
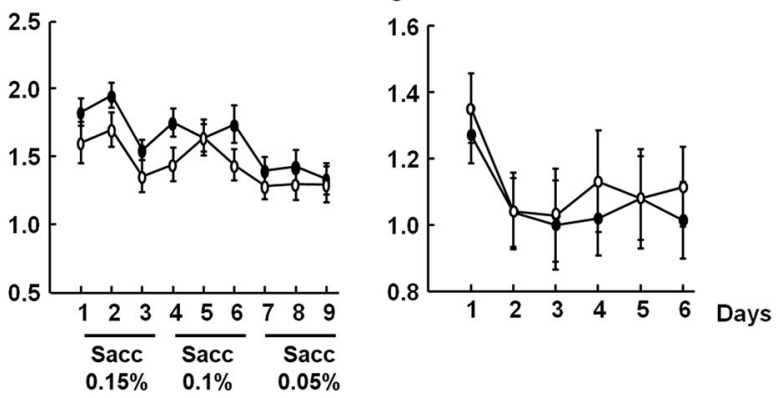

Fig. 4 Evaluation of CBD's effect on motivation. a Schematic diagram of oral CBD self-administration including the different experimental phases: training, substitution, and consumption under a fixed ratio 1 (FR1) schedule. The dots represent the means \pm SEM of the number of effective responses $\mathbf{b}$ and the fluid intake e during training, the number of effective responses $\mathbf{c}$ and the fluid intake $\mathbf{f}$ during substitution, and the number of effective responses $\mathbf{d}$ and the fluid intake $\mathbf{g}$ during consumption under a FR1 schedule

it did not exhibit drug-abuse potential in any of the different behavioral assays evaluated, including CPP, spontaneous withdrawal, and oral self-administration. In light of the data available, the classification of CBD by certain administrations should be reconsidered, as the categorization of $\mathrm{CBD}$ as a drug with abuse potential is not based on evidence and is pharmacologically unsupported.

In addition, no significant side effects have been observed in any of the preclinical or clinical studies using CBD to date. Indeed, CBD is present in nabiximols (marketed as Sativex ${ }^{\circledR}$ ) currently approved for the treatment of spasticity in multiple sclerosis in several countries in Europe. Therefore, there is a large body of evidence supporting its safety and lack of side effects. Together with the established literature, the results of this study may encourage the acceleration of the development of the basic and clinical studies needed to elucidate the potential therapeutic use of $C B D$ for the treatment of a wide variety of neuropsychiatric disorders.

\section{ACKNOWLEDGEMENTS}

The authors disclosed receipt of the following financial support for the research, authorship, and/or publication of this article. This work was supported by the "Instituto de Salud Carlos III" (RETICS, RD12/0028/0019), "Plan Nacional Sobre Drogas" (PNSD 2016/016), and "Ministerio de Economía y Competitividad" (FIS, PI14/00438) to JM. AVM is a predoctoral fellow supported by "Plan Nacional Sobre Drogas" (PNSD 2016/016).

\section{AUTHOR CONTRIBUTIONS}

AVM, MSGG, JMR, and CMN carried out the experimental procedures, undertook the statistical analysis, and took part in the interpretation of the results obtained. AVM, MSGG, JMR, CMN, and FN wrote the first draft of the manuscript. MSGG and JM designed the study, wrote the protocol, interpreted the results, and approved the final manuscript.

\section{ADDITIONAL INFORMATION}

Competing interests: The authors declare no competing interests.

Publisher's note: Springer Nature remains neutral with regard to jurisdictional claims in published maps and institutional affiliations.

\section{REFERENCES}

1. Pertwee RG. The diverse $C B 1$ and $C B 2$ receptor pharmacology of three plant cannabinoids: delta9-tetrahydrocannabinol, cannabidiol and delta9tetrahydrocannabivarin. Br J Pharmacol. 2008;153:199-215.

2. Atakan Z. Cannabis, a complex plant: different compounds and different effects on individuals. Ther Adv Psychopharmacol. 2012;2:241-54.

3. ElSohly MA, Radwan MM, Gul W, Chandra S, Galal A. Phytochemistry of Cannabis sativa L. In: Kinghorn AD, Falk H, Gibbons S, Kobayashi Ji, editors. Phytocannabinoids: unraveling the complex chemistry and pharmacology of Cannabis sativa. Cham: Springer International Publishing; 2017. p. 1-36.

4. Gaoni Y, Mechoulam R. Isolation, structure, and partial synthesis of an active constituent of Hashish. J Am Chem Soc. 1964;86:1646-7.

5. Zhang PW, Ishiguro $H$, Ohtsuki T, Hess J, Carillo F, Walther $D$, et al. Human cannabinoid receptor $1: 5^{\prime}$ exons, candidate regulatory regions, polymorphisms, 
haplotypes and association with polysubstance abuse. Mol Psychiatry. 2004;9:916-31.

6. Mechoulam R, Shvo Y, Hashish I. The structure of cannabidiol. Tetrahedron. 1963;19:2073-8.

7. Zlebnik NE, Cheer JF. Beyond the $\mathrm{CB} 1$ receptor: is cannabidiol the answer for disorders of motivation? Annu Rev Neurosci. 2016:39:1-17.

8. Carlini EA, Cunha JM. Hypnotic and antiepileptic effects of cannabidiol. J Clin Pharmacol. 1981;21:417S-27S.

9. Devinsky O, Cilio MR, Cross H, Fernandez-Ruiz J, French J, Hill C, et al. Cannabidiol: pharmacology and potential therapeutic role in epilepsy and other neuropsychiatric disorders. Epilepsia. 2014;55:791-802.

10. Devinsky O, Marsh E, Friedman D, Thiele E, Laux L, Sullivan J, et al. Cannabidiol in patients with treatment-resistant epilepsy: an open-label interventional trial. Lancet Neurol. 2016;15:270-8.

11. Giacoppo S, Soundara Rajan T, Galuppo M, Pollastro F, Grassi G, Bramanti P, et al. Purified Cannabidiol, the main non-psychotropic component of Cannabis sativa, alone, counteracts neuronal apoptosis in experimental multiple sclerosis. Eur Rev Med Pharmacol Sci. 2015;19:4906-19.

12. Kozela E, Lev N, Kaushansky N, Eilam R, Rimmerman N, Levy R, et al. Cannabidiol inhibits pathogenic $\mathrm{T}$ cells, decreases spinal microglial activation and ameliorates multiple sclerosis-like disease in $\mathrm{C} 57 \mathrm{BL} / 6$ mice. $\mathrm{Br} J$ Pharmacol. 2011;163:1507-19.

13. Chagas MH, Zuardi AW, Tumas V, Pena-Pereira MA, Sobreira ET, Bergamaschi MM, et al. Effects of cannabidiol in the treatment of patients with Parkinson's disease: an exploratory double-blind trial. J Psychopharmacol. 2014;28:1088-98.

14. Zuardi AW, Crippa JA, Hallak JE, Pinto JP, Chagas MH, Rodrigues GG, et al. Cannabidiol for the treatment of psychosis in Parkinson's disease. J Psychopharmacol. 2009;23:979-83.

15. Cheng D, Spiro AS, Jenner AM, Garner B, Karl T. Long-term cannabidiol treatment prevents the development of social recognition memory deficits in Alzheimer's disease transgenic mice. J Alzheimers Dis. 2014;42:1383-96.

16. Martin-Moreno AM, Reigada D, Ramirez BG, Mechoulam R, Innamorato N, Cuadrado $\mathrm{A}$, et al. Cannabidiol and other cannabinoids reduce microglial activation in vitro and in vivo: relevance to Alzheimer's disease. Mol Pharmacol. 2011;79:964-73.

17. Osborne AL, Solowij N, Weston-Green K. A systematic review of the effect of cannabidiol on cognitive function: relevance to schizophrenia. Neurosci Biobehav Rev. 2017;72:310-24.

18. Liput DJ, Hammell DC, Stinchcomb AL, Nixon K. Transdermal delivery of cannabidiol attenuates binge alcohol-induced neurodegeneration in a rodent model of an alcohol use disorder. Pharmacol Biochem Behav. 2013;111:120-7.

19. Schiavon AP, Bonato JM, Milani H, Guimaraes FS, Weffort de Oliveira RM. Influence of single and repeated cannabidiol administration on emotional behavior and markers of cell proliferation and neurogenesis in non-stressed mice. Prog Neuropsychopharmacol Biol Psychiatry. 2016;64:27-34.

20. Blessing EM, Steenkamp MM, Manzanares J, Marmar CR. Cannabidiol as a potential treatment for anxiety disorders. Neurotherapeutics. 2015;12:825-36.

21. Guimaraes FS, Chiaretti TM, Graeff FG, Zuardi AW. Antianxiety effect of cannabidiol in the elevated plus-maze. Psychopharmacol (Berl). 1990;100:558-9.

22. Moreira FA, Aguiar DC, Guimaraes FS. Anxiolytic-like effect of cannabidiol in the rat Vogel conflict test. Prog Neuropsychopharmacol Biol Psychiatry. 2006;30:1466-71.

23. Resstel LB, Joca SR, Moreira FA, Correa FM, Guimaraes FS. Effects of cannabidiol and diazepam on behavioral and cardiovascular responses induced by contextual conditioned fear in rats. Behav Brain Res. 2006;172:294-8.

24. Sartim AG, Guimaraes FS, Joca SR. Antidepressant-like effect of cannabidiol injection into the ventral medial prefrontal cortex-possible involvement of 5HT1A and CB1 receptors. Behav Brain Res. 2016;303:218-27.

25. Linge R, Jimenez-Sanchez L, Campa L, Pilar-Cuellar F, Vidal R, Pazos A, et al. Cannabidiol induces rapid-acting antidepressant-like effects and enhances cortical 5-HT/glutamate neurotransmission: role of 5-HT1A receptors. Neuropharmacology. 2016;103:16-26.

26. Zanelati TV, Biojone C, Moreira FA, Guimaraes FS, Joca SR. Antidepressant-like effects of cannabidiol in mice: possible involvement of $5-\mathrm{HT} 1 \mathrm{~A}$ receptors. $\mathrm{Br} J$ Pharmacol. 2010;159:122-8.

27. Leweke FM, Piomelli D, Pahlisch F, Muhl D, Gerth CW, Hoyer C, et al. Cannabidiol enhances anandamide signaling and alleviates psychotic symptoms of schizophrenia. Transl Psychiatry. 2012;2:e94.

28. Leweke FM, Mueller JK, Lange B, Rohleder C. Therapeutic potential of cannabinoids in psychosis. Biol Psychiatry. 2016;79:604-12.

29. Long LE, Malone DT, Taylor DA. Cannabidiol reverses MK-801-induced disruption of prepulse inhibition in mice. Neuropsychopharmacology. 2006;31:795-803.

30. Moreira FA, Guimaraes FS. Cannabidiol inhibits the hyperlocomotion induced by psychotomimetic drugs in mice. Eur J Pharmacol. 2005;512:199-205.
31. Peres FF, Levin R, Almeida V, Zuardi AW, Hallak JE, Crippa JA, et al. Cannabidiol, among other cannabinoid drugs, modulates prepulse inhibition of startle in the SHR animal model: implications for schizophrenia pharmacotherapy. Front Pharmacol. 2016;7:303.

32. Zuardi AW, Rodrigues JA, Cunha JM. Effects of cannabidiol in animal models predictive of antipsychotic activity. Psychopharmacol (Berl). 1991;104:260-4.

33. Izzo AA, Borrelli F, Capasso R, Di Marzo V, Mechoulam R. Non-psychotropic plant cannabinoids: new therapeutic opportunities from an ancient herb. Trends Pharmacol Sci. 2009;30:515-27.

34. Campos AC, Fogaca MV, Sonego AB, Guimaraes FS. Cannabidiol, neuroprotection and neuropsychiatric disorders. Pharmacol Res. 2016;112:119-27.

35. Ibeas Bih C, Chen T, Nunn AV, Bazelot M, Dallas M, Whalley BJ. Molecular targets of cannabidiol in neurological disorders. Neurotherapeutics. 2015;12:699-730.

36. Campos AC, Ferreira FR, Guimaraes FS. Cannabidiol blocks long-lasting behavioral consequences of predator threat stress: possible involvement of 5HT1A receptors. J Psychiatr Res. 2012;46:1501-10.

37. Bisogno T, Hanus L, De Petrocellis L, Tchilibon S, Ponde DE, Brandi I, et al. Molecular targets for cannabidiol and its synthetic analogues: effect on vanilloid VR1 receptors and on the cellular uptake and enzymatic hydrolysis of anandamide. Br J Pharmacol. 2001;134:845-52.

38. Carrier EJ, Auchampach JA, Hillard CJ. Inhibition of an equilibrative nucleoside transporter by cannabidiol: a mechanism of cannabinoid immunosuppression. Proc Natl Acad Sci USA. 2006;103:7895-900.

39. Massi $P$, Valenti $M$, Bolognini $D$, Parolaro $D$. Expression and function of the endocannabinoid system in glial cells. Curr Pharm Des. 2008;14:2289-98.

40. Russo EB. Cannabidiol claims and misconceptions. Trends Pharmacol Sci. 2017;38:198-201.

41. Thomas A, Baillie GL, Phillips AM, Razdan RK, Ross RA, Pertwee RG. Cannabidiol displays unexpectedly high potency as an antagonist of $C B 1$ and $C B 2$ receptor agonists in vitro. Br J Pharmacol. 2007;150:613-23.

42. Petitet F, Jeantaud B, Reibaud M, Imperato A, Dubroeucq MC. Complex pharmacology of natural cannabinoids: evidence for partial agonist activity of delta9tetrahydrocannabinol and antagonist activity of cannabidiol on rat brain cannabinoid receptors. Life Sci. 1998;63:PL1-6.

43. Comprehensive Drug Abuse Prevention and Control Act of 1970 (1970). Available at: https://www.gpo.gov/fdsys/pkg/STATUTE-84/pdf/STATUTE-84-Pg1236.pdf. Accessed on 4 May 2018.

44. Controlled Drugs and Substance Act (2018). Available at: https://laws-lois.justice. gc.ca/PDF/C-38.8.pdf. Accessed on 4 May 2018.

45. Martin-Santos R, Crippa JA, Batalla A, Bhattacharyya S, Atakan Z, Borgwardt S, et al. Acute effects of a single, oral dose of d9-tetrahydrocannabinol (THC) and cannabidiol (CBD) administration in healthy volunteers. Curr Pharm Des. 2012;18:4966-79.

46. Fusar-Poli P, Crippa JA, Bhattacharyya S, Borgwardt SJ, Allen P, Martin-Santos R, et al. Distinct effects of \{delta\}9-tetrahydrocannabinol and cannabidiol on neural activation during emotional processing. Arch Gen Psychiatry. 2009;66:95-105.

47. Winton-Brown TT, Allen P, Bhattacharyya S, Borgwardt SJ, Fusar-Poli P, Crippa JA, et al. Modulation of auditory and visual processing by delta-9-tetrahydrocannabinol and cannabidiol: an FMRI study. Neuropsychopharmacology. 2011;36:1340-8.

48. Parker LA, Burton P, Sorge RE, Yakiwchuk C, Mechoulam R. Effect of low doses of delta9-tetrahydrocannabinol and cannabidiol on the extinction of cocaineinduced and amphetamine-induced conditioned place preference learning in rats. Psychopharmacol (Berl). 2004;175:360-6.

49. Vann RE, Gamage TF, Warner JA, Marshall EM, Taylor NL, Martin BR, et al. Divergent effects of cannabidiol on the discriminative stimulus and place conditioning effects of Delta(9)-tetrahydrocannabinol. Drug Alcohol Depend. 2008;94:191-8.

50. Ortega-Alvaro A, Ternianov A, Aracil-Fernandez A, Navarrete F, Garcia-Gutierrez MS, Manzanares J. Role of cannabinoid CB2 receptor in the reinforcing actions of ethanol. Addict Biol. 2015;20:43-55.

51. Pastor A, Farre M, Fito M, Fernandez-Aranda F, de la Torre R. Analysis of ECs and related compounds in plasma: artifactual isomerization and ex vivo enzymatic generation of 2-MGs. J Lipid Res. 2014;55:966-77.

52. Aracil-Fernández A, Almela $P$, Manzanares J. Pregabalin and topiramate regulate behavioural and brain gene transcription changes induced by spontaneous cannabinoid withdrawal in mice. Addict Biol. 2013;18:252-62.

53. Oliva JM, Ortiz S, Palomo T, Manzanares J. Behavioural and gene transcription alterations induced by spontaneous cannabinoid withdrawal in mice. J Neurochem. 2003;85:94-104.

54. Navarette F, Rubio G, Manzanares J. Effects of naltrexone plus topiramate on ethanol self-administration and tyrosine hydroxylase gene expression changes. Addict Biol. 2013;19:862-73.

55. Katsidoni V, Anagnostou I, Panagis G. Cannabidiol inhibits the reward-facilitating effect of morphine: involvement of 5-HT1A receptors in the dorsal raphe nucleus. Addict Biol. 2013;18:286-96. 
Cannabidiol does not display drug abuse potential in mice behavior A Viudez-Martínez et al.

364

56. Bhargava HN. Effect of some cannabinoids on naloxone-precipitated abstinence in morphine-dependent mice. Psychopharmacol (Berl). 1976;49:267-70.

57. Ren Y, Whittard J, Higuera-Matas A, Morris CV, Hurd YL. Cannabidiol, a nonpsychotropic component of cannabis, inhibits cue-induced heroin seeking and normalizes discrete mesolimbic neuronal disturbances. J Neurosci. 2009;29:14764-9.

58. Weiss FLA, Wagner G, Deness G, Kerr T, Watry D, Suto N. Transdermal CBD attenuates cocaine intake in rats with addiction-linked cocaine history. San Diego (CA): Annual Meeting Society for Neuroscience; 2016.

59. Viudez-Martinez A, Garcia-Gutierrez MS, Navarron CM, Morales-Calero MI, Navarette F, Torres-Suarez Al, et al. Cannabidiol reduces ethanol consumption, motivation and relapse in mice. Addict Biol. 2017;23:154-64.

60. Crippa JA, Zuardi AW, Martin-Santos R, Bhattacharyya S, Atakan Z, McGuire P, et al. Cannabis and anxiety: a critical review of the evidence. Hum Psychopharmacol. 2009;24:515-23.

61. Allsop DJ, Copeland J, Lintzeris N, Dunlop AJ, Montebello M, Sadler C, et al. Nabiximols as an agonist replacement therapy during cannabis withdrawal: a randomized clinical trial. JAMA Psychiatry. 2014;71:281-91.
62. Haney M, Malcolm RJ, Babalonis S, Nuzzo PA, Cooper ZD, Bedi G, et al. Oral cannabidiol does not alter the subjective, reinforcing or cardiovascular effects of smoked cannabis. Neuropsychopharmacology. 2016;41:1974-82.

63. Itzhak Y, Martin JL. Cocaine-induced conditioned place preference in mice: induction, extinction and reinstatement by related psychostimulants. Neuropsychopharmacology. 2002;26:130-4.

64. Navarrete F, Rodriguez-Arias M, Martin-Garcia E, Navarro D, Garcia-Gutierrez MS, Aguilar MA, et al. Role of $C B 2$ cannabinoid receptors in the rewarding, reinforcing, and physical effects of nicotine. Neuropsychopharmacology. 2013;38: 2515-24.

65. Vezina $\mathrm{P}$, Stewart J. Morphine conditioned place preference and locomotion: the effect of confinement during training. Psychopharmacol (Berl). 1987; 93:257-60.

66. Oliva JM, Ortiz S, Palomo T, Manzanares J. Spontaneous cannabinoid withdrawal produces a differential time-related responsiveness in cannabinoid CB1 receptor gene expression in the mouse brain. J Psychopharmacol. 2004;18: 59-65. 